\title{
Effect of Tissue Culture in Vegetable Improvement
}

\author{
Amba Kumari $^{*}$, Dibyanshu Shekhar ${ }^{1}$, M. S. Kundu ${ }^{2}$, \\ Ram Prawesh Prasad $^{1}$, A. P. Rakesh ${ }^{1}$ and Chandan Kumar ${ }^{1}$ \\ ${ }^{1}$ Krishi Vigyan Kendra, Jale, Darbhanga, Bihar-847302, India \\ ${ }^{2}$ Dr.Rajendra Prasad Central Agricultural University, Pusa, Samastipur, Bihar-848125, India \\ *Corresponding author
}

\section{A B S T R A C T}

\section{Keywords}

In-vitro plant regeneration, Vegetable crops, Somatic hybridization

\section{Article Info}

Accepted: 04 August 2020 Available Online: 10 September 2020

\begin{abstract}
As an emerging technology, the plant tissue culture has a great impact on agriculture, through providing plants needed to meet the ever increasing world demand. It has made significant advancement in the field of vegetable crops. Plant tissue culture represents the most promising areas of application at present time and giving an outlook into the future. All biotechnological approaches like genetic Meristem culture, haploid induction or Somatic hybridization in the field of vegetable crops to improve traits strongly depends on an efficient in-vitro plant regeneration system. Potato viruses are major causes of yield loss and reduction in quality of seed tubers. Meristem culture with thermotherapy applied all three viruses PVX, PVS, PLRV eliminated with success rate of $86 \%, 100 \%$ and $83 \%$ respectively (Biniam and Tadesse, 2007). Many sources of useful genes cannot be included in crop improvement because of sexual incompatibilities, while it can be readily achieved by somatic hybridization in potato (Tiwari et al., 2011). Tomato is highly prone to biotic stress, especially diseases, insects and nematodes. Tissue culture technology can be used with the aim of transfer of important traits from the wild species to the already cultivated and popular species through somatic hybridization (Kharkongar et al., 2013).Cryopreservation is done for long term preservation of important planting material to minimize time and cost on manpower, chemicals. Cryopreservation has done in different vegetables e.g. shoot primordial of melon by slow freezing (Ishikawa et al., 1996). Apical meristem of garlic by vitrification (Niwata et al., 1995). The tissue culture techniques enable to produce homozygous plants in relatively short time period through the protoplast fusion, anther and microspore culture instead of conventional breeding( Hussain et al., 2012). Current and future status of plant tissue culture in vegetable crops are production of improved varieties, conservation of endangered species, production of secondary metabolites or plant-made vaccines or antibodies through cell suspension culture on large scale. Providing planting material of plants whose multiplication is not possible through seed to meet the ever increasing world demand.
\end{abstract}

\section{Introduction}

Production of improved crop varieties tolerant to salinity, drought, and heat stresses.
Production of disease- free plants (virus) in potato, brinjal and tomato. Genetic engineering can make possible a number of improved crop varieties with high yield 
potential and resistance against pests. Genetic transformation technology relies on the technical aspects of plant tissue culture and molecular biology for production of improved crop varieties, production of disease-free plants (virus), genetic transformation, production of secondary metabolites, production of varieties tolerant to salinity, drought and heat stresses

\section{Techniques of tissue culture}

Meristem culture

Embryo Rescue

Somatic Hybridization

Cryopreservation

Haploid and Double Haploid

\section{Meristem Culture}

In vitro culture of youngest leaf primordial most often excised from the shoot apex. Meristem culture is the in vitro culture of a generally shiny special dome-like structure mea-suring less than $0.1 \mathrm{~mm}$ in length and only one or two pairs of the youngest leaf primordia, most often excised from the shoot apex.

Importance of Meristem Culture

Virus eradication,

Micro-propagation and

Storage of genetic resources

\section{Case study: I (Biniam and Tadesse, 2007)}

Potato viruses are the major causes of yield loss and reduction in quality of seed tubers in Eritrea. A study was conducted to investigate the prevalence of viruses in potatoes (Solanum tuberosum L.) grown in Eritrea and to evaluate methods for their elimination. Five of the most important potato viruses, PVX, PVY, PLRV, PVS and PVA, were detected in single and multiple infections. Virus elimination techniques were tested using in vitro plantlets of T. embaba established from field-grown tubers. Presence of PVX, PLRV and PVS was confirmed by ELISA test. The treatment was successful in eliminating only PLRV but failed to eliminate PVX and PVS. When meristem culture was combined with thermotherapy treatment for one week all three viruses PVX, PLRV and PVS were eliminated with a success rate of 86,83 and $100 \%$, respectively.

The proportion of meristem of "Tsaeda embaba" regenerated in the different thermotherapy treatments

\begin{tabular}{|l|c|c|c||}
\hline Treatment & $\begin{array}{c}\text { No. of meristems } \\
\text { excised }\end{array}$ & $\begin{array}{c}\text { No. of meristems } \\
\text { regenerated }\end{array}$ & $\begin{array}{c}\text { \% of meristems } \\
\text { regenerated }\end{array}$ \\
\hline Untreated & 20 & 7 & 35 \\
Thermotherapy for one week & 20 & 9 & 45 \\
Thermotherapy for two weeks & 11 & 4 & 36 \\
\hline
\end{tabular}

Number of virus free Tsaeda embaba plants produced at different treatments for the various viruses (number in brackets indicate percentage of virus free plants)

\begin{tabular}{|l|c|c|c|}
\hline \multicolumn{1}{|c|}{ Treatments } & PVX & PVS & PLRV \\
\hline 1 week HT & $0 / 15(0 \%)$ & $0 / 5(0 \%)$ & $8 / 15(53 \%)$ \\
2 week HT & $0 / 11(0 \%)$ & $0 / 3(0 \%)$ & $10 / 11(91 \%)$ \\
1 week HT + MC & $6 / 7(86 \%)$ & $2 / 2(100 \%)$ & $5 / 6(83 \%)$ \\
2 week HT + MC & $1 / 4(25 \%)$ & $1 / 1(100 \%)$ & $4 / 4(100 \%)$ \\
MC & $0 / 5(0 \%)$ & $1 / 3(33 \%)$ & $6 / 6(100 \%)$ \\
\hline
\end{tabular}

$\mathrm{HT}=$ Heat treatment, $\mathrm{MC}=$ Meristem Culture

Sprouted tubers were taken as a source of explant in in vitro establishment. Mother plant for sub culturing were tested for virus by ELISA and RT- PCR. Thermotherapy at the temperature $37^{\circ}$ and 16 hour photoperiod for two, three and four weeks. The surviving plants were sub cultured and used for ELISA and RT-PCR test. Meristem excision by apical meristem with one or two leaf primordial. Cultured in MS (Murashige and Skoog, 1962) medium, supplemented with PGRS. Kept under controlled environment in growth chamber with 16 hour photoperiod, 
$27^{\circ} / 20^{\circ}$ day/night temperature. Rate of success of virus eradication is assayed by ELISA/ RT- PCR test.

\section{Embryo rescue}

Used to promote the development of immature or weak embryo into a viable plants. The embryos were extracted from immature fruit and cultured on artificial nutrient medium. It is utilized to obtain seed from interspecific/wide hybridization. Embryo rescue is done to overcome certain barriers to fertilization. The term "embryo rescue" refers to a number of in vitro techniques whose purpose is to promote the development of an immature or weak embryo into a viable plant. Embryo rescue has been widely used for producing plants from hybridizations in which failure of endosperm to properly develop causes embryo abortion. In embryo rescue procedures, the artificial nutrient medium serves as a substitute for the endosperm, thereby allowing the embryo to continue its development. Embryo rescue techniques are among the oldest and most successful in vitro procedures.

\section{Case study II}

Tomato is highly prone to biotic stresses especially diseases, insects and nematodes. Its aim is to transfer important traits from the wild species to the already cultivated species. Genes against disease, insects and nematode resistant are present in wild species but it has not been easy to transfer these genes in cultivated species due to problem in crossability. Seeds of three different species are taken, it is grown in trays then transplanted in plot. Flowers are allowed to self - pollinate and cross between the various genotype were made in all possible combinations. Factors involved in Embryo rescue is media MS media (Murashige and Skoog, 1962). Temperature requirements is $25-30^{\circ} \mathrm{C}$. Culture to be initiated prior to embryo abortion.

Percent fruit set on selfing and interspecific crosses of the four parents and three species of Solanum lycopersicum used in experiments

Solanum lycopersicum (MT-3) x Solanum pimpinellifolium (35\%) and S. lycopersicum (KA) x Solanum pimpinellifolium (32\%) have maximum fruit set percentage. $S$. lycopersicum, MT-3(45\%) and $S$. lycopersicum variety KA $(41 \%)$ gave maximum fruit set. Fruit set on selfing of $\mathrm{S}$. lycopersicum was also good. The interspecific cross of Solanum lycopersicum variety MT-3 with $S$. peruvianum, and the cross of Solanum lycopersicum var. KA with $S$. peruvianum gave $7 \%$ and $8 \%$ fruit set. S. peruvianum (wild species used as a female parent and $S$. lycopersicum as a pollen donor resulted in zero fruit set). The crosses which yield low fruit set i.e. S. lycopersicum $x$ S. peruvianum were selected for embryo rescue. Crosses between the various genotypes were made in all possible combinations. Crosses which yielded a low fruit set, i.e. S. lycopersicum $x$ $S$. peruvianum were used for embryo rescue. The best growth response was seen with the embryos which were taken out from immature fruits, after 25 days of pollination. Cultured on MS medium supplemented with $1.0 \mathrm{mg} / 1$ GA3, 0.1 mg/1NAA, 0.5 mg/1BAP. Photoperiod $16 / 8 \mathrm{~h}$ light/dark period, $25^{\circ} \mathrm{C}$, $65 \%$ R.H. Putative hybrids obtained.

\section{Somatic hybridization}

Development of hybrid plants through the fusion of somatic protoplast of two different plant species varieties is called somatic hybridization. Many sources of useful genes cannot be included in crop improvement programme because of sexual incompatibilities. Genetic transformation is expensive approach require isolation, Identification and cloning, while it can be 
achieved through somatic hybridization. It enables a development of tetraploid somatic hybrid between diploid wild species and dihaploid. In somatic hybridization techniques isolation of protoplast, fusion of Protoplast of desired species/varieties, identification and selection of somatic hybrid cells, regeneration of hybrid plants. Isolation of protoplast is done by mechanical and enzymatic method. In mechanical method cutting of cell wall with knife. It is used for the vacuolated cells like onion bulb scale, radish and beet root tissues. It is a laborious and tedious process. In enzymatic method enzyme e.g. cellulase, pectinase is used. In enzymatic method leaf sterilization and removal of epidermis is done. Protoplast fusion is done through spontaneous and induced fusion. Spontaneous fusion is classified into two types intraspecific and intergeneric. Intraspecific produce homokaryon. Intergeneric is of no importance. Induced fusion is classified into chemofusion, mechanical fusion and electrofusion. In chemofusion polyethylene glycol and polyvinyl alcohol is used. In mechanical fusion micromanipulator is used. In electrofusion electric stimulation is used. Protoplast fuses spontaneously during isolation process mainly due to physical contact.

\section{Case study III}

\section{Somatic hybridization in potato improvement}

Gene transfer is the basis for almost all crop improvement including potato: conventionally it is achieved through sexual hybridization. This rather limits the range of species from which gene flow can occur into a crop species. Wild species have contributed remarkably to the success of latter, they allowed the crops to retain their commercial status. As a result plant breeders have sought to utilized an increasing number of wild species as a sources as a source of valuable genes ranging from disease resistance to yield and produce quality. But many sources of useful genes cannot be included in crop improvement programme primarily because of sexual incompatibilities. Genetic transformation, a focused and direct gene transfer approach, require identification, isolation and cloning of the concerned genes. Further it is expensive and technically most exacting. However some characters of interest may be govern by two or more and yet unknown genes. Finally transfer of cytoplasmic organelle, viz, chloroplast and mitochondria may often be desired objectives: this, however is not possible through genetic transformation, while it can readily achieved by somatic hybridization. Utilization of the wild tuber-bearing diploid species has been remained untapped potential source for transferring resistance trait into common potato. Barrier between the cultivated potato and the many wild species has proved a difficult task, even when unconventional crossing methods are use.

\section{Cryopreservation}

Germplasm conservation worldwide is increasingly becoming an essential activity due to high rate of disappearance of plant species and the increased need for safeguarding the floristic patrimony of the countries, to keep the genetic background of a crop and to avoid the loss of the conserved patrimony due to natural disasters, whether biotic or abiotic stress. The plant species which do not produce seeds (sterile plants) or which have recalcitrant seed that cannot be stored for long period of time can successfully be preserved via in vitro techniques for the maintenance of gene banks. Cryopreservation plays a vital role in the long-term in vitro conservation of essential biological material and genetic resources. It involves the storage of in vitro cells or tissues in liquid nitrogen 
that results in cryo -injury on the exposure of tissues to physical and chemical stresses. Successful cryopreservation is often ascertained by cell and tissue survival and the ability to re-grow or regenerate into complete plants or form new colonies. Storage of living tissues at ultra-low temperature. Long term preservation/maintenance of important planting required for maintenance through repeated sub-culturing under in vitro condition. Storage of living tissues at ultralow temperatures $\left(-196^{\circ} \mathrm{c}\right)$. Used for propagated species (root and tubers, ornamental, fruit trees), Recalcitrant seed species(coconut, coffee).Cryobiology is the effects of extremely low temperatures on material/germplasm to minimize time and cost on manpower, chemicals and other consumable's. Usually rapid thawing to avoid damage from ice crystal. Putting the sample in a warm water bath $\left(35-45^{\circ} \mathrm{c}\right)$. Thawed cells must be washed of cryo- protectants and nursed back to normal. Shoot primordial of melon by slow pre freezing (Ishikawa et al., 1996). Shoot tip of cassava by slow freezing (Escobar et al., 1997). Shoot tip of sweet potato by Towill and Jarret, 1992). Shoot apices of yam by (Onwueme and Zanga, 1996). Apical meristems of garlic by vetrification (Niwata et al., 1995) (Fig. 1-5 and Table 1).

Table.1

\begin{tabular}{|l|l|l|}
\hline $\begin{array}{l}\text { Vegetable } \\
\text { Crops }\end{array}$ & Commercial varieties & $\begin{array}{l}\text { Released } \\
\text { country }\end{array}$ \\
\hline Asparagus & Andreas (super male) & France \\
\cline { 2 - 3 } & Golia, Ringo, Argo & Italy \\
\cline { 2 - 3 } & Guelph (Super male) & Canada \\
\hline Chilli & Tajo, pekin, Olmo & Spain \\
\hline Brinjal & Cristal, Seven, Milar, Petra & Spain \\
\hline
\end{tabular}

Fig.1

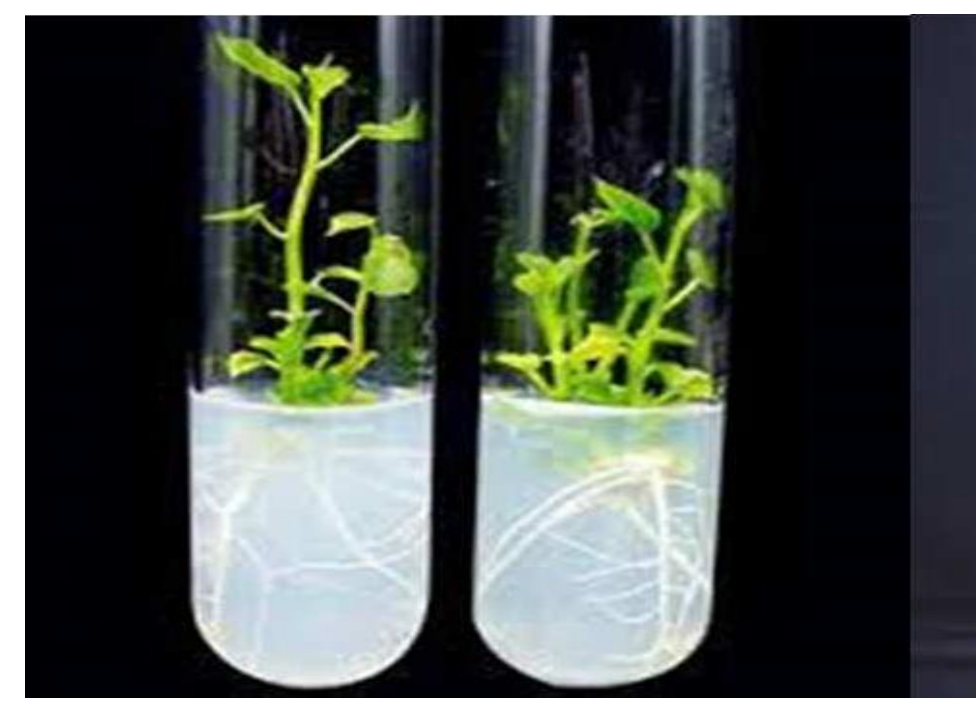




\section{Fig.2}

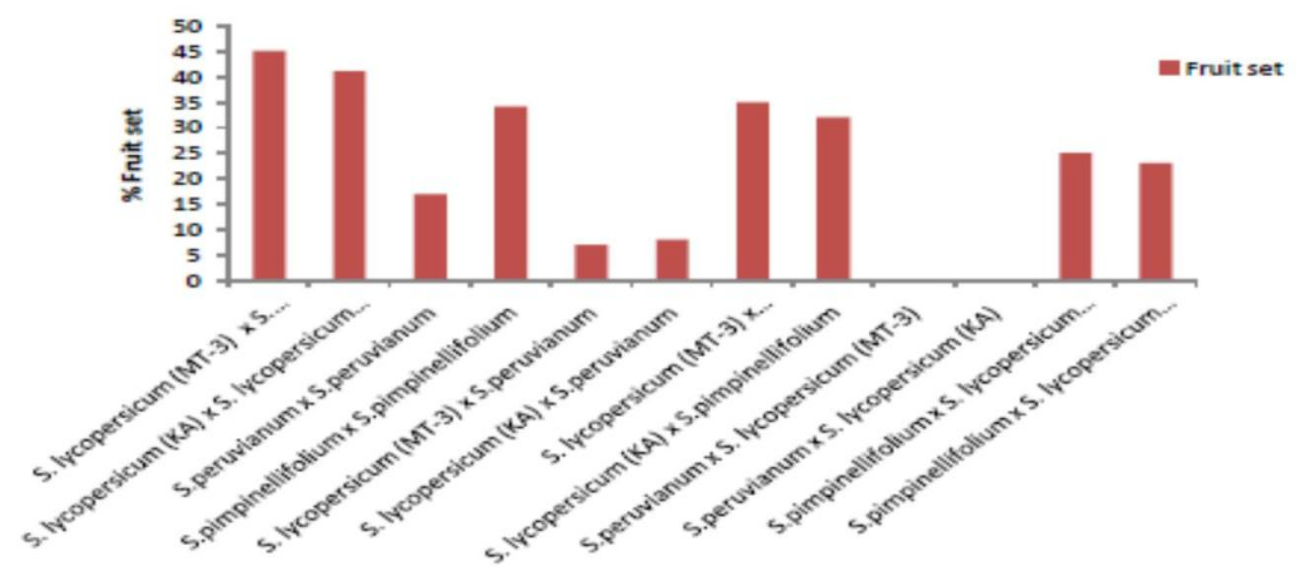

Fig.3 Embryo rescued plantlets of S. lycopersicum (Megha Tomato-3 S. peruvianum)

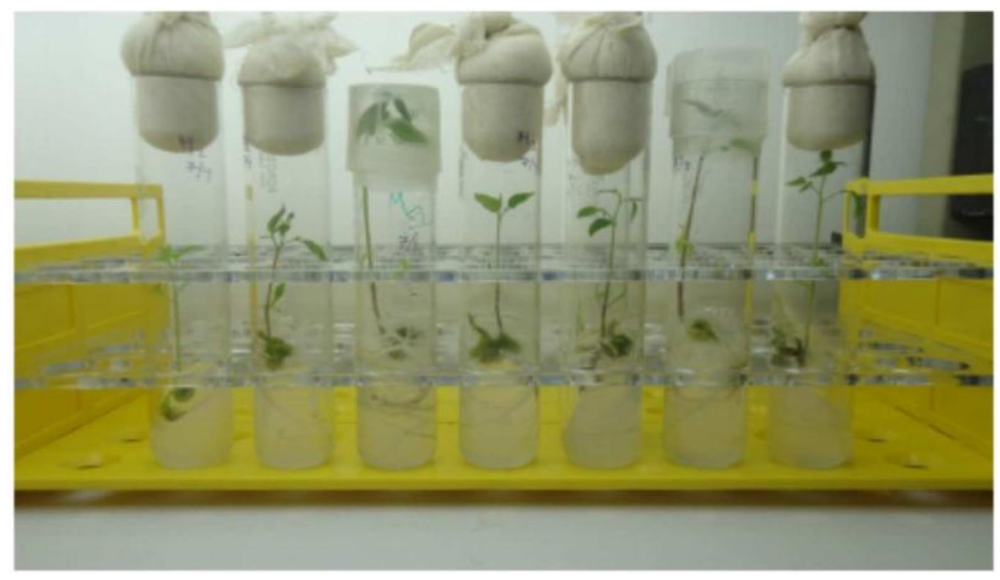

Fig.4 Hardening of embryo rescued plants from S. lycopersicim x S. peruvianum inside the plant growth chamber

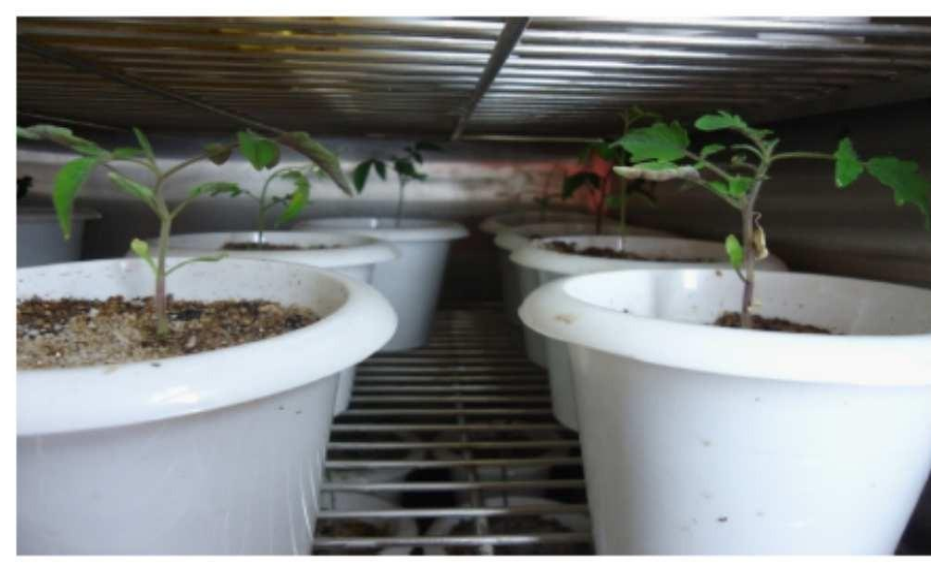


Fig.5 List of varieties released through DH in vegetable crops
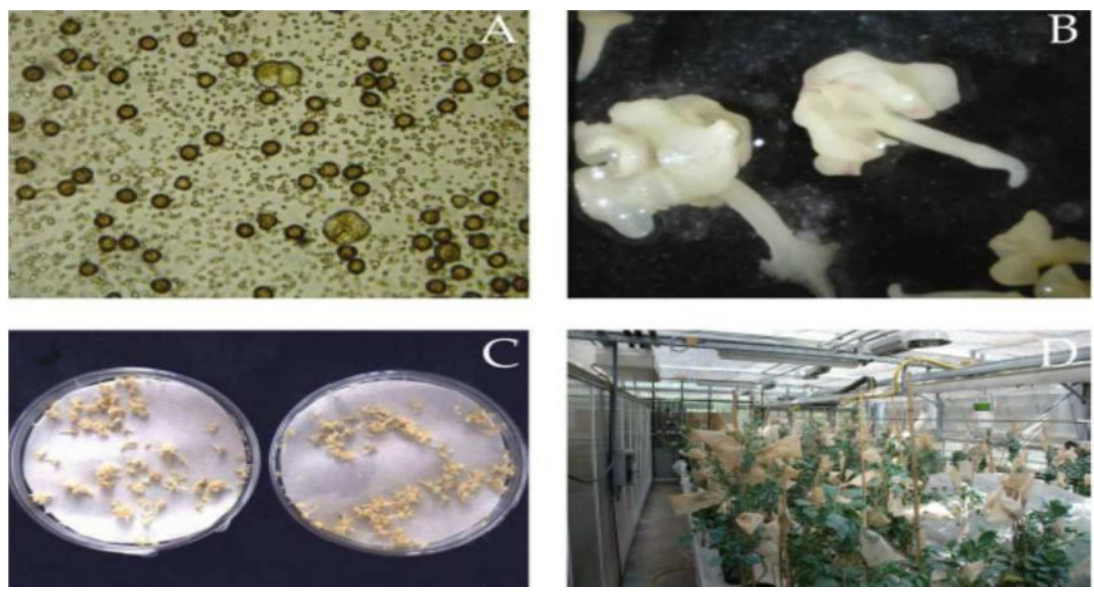

\section{Haploids and doubled haploids}

Haploids are plants (sporophytes) that contain a gametic chromosome number (n). They can originate spontaneously in nature or as a result of various induction techniques. Spontaneous development of haploid plants has been known since 1922, when Blakeslee first described this phenomenon in Datura stramonium (Blakeslee et al., 1922); this was subsequently followed by similar reports in tobacco (Nicotiana tabacum), wheat (Triticum aestivum) and several other species (Forster et al., 2007). However, spontaneous occurrence is a rare event and therefore of limited practical value. The potential of haploidy for plant breeding arose in 1964 with the achievement of haploid embryo formation from in vitro culture of Datura anthers (Guha and Maheshwari, 1964, 1966), which was followed by successful in vitro haploid production in tobacco (Nitsch and Nitsch, 1969). Many attempts have been made since then, resulting in published protocols for over 250 plant species belonging to almost all families of the plant kingdom (reviewed in Maluszynski et al., 2003). In fact, under optimal conditions, doubled haploids $(\mathrm{DH})$ have been routinely used inbreeding for several decades, although their common use is still limited to selected species. There are several reasons for this. These might be categorized as biological, based on plant status (annual, biannual, perennial, autogamous, allogamous, vegetatively propagated) and flower morphology or technical, which are the result of the feasibility and efficiency of $\mathrm{DH}$ induction protocol.

\section{Production of haploids and doubled haploids}

Haploids produced from diploid species $(2 n=2 x)$, known as monoploids, contain only one set of chromosomes in the sporophytic phase $(2 n=x)$. They are smaller and exhibit a lower plant vigor compared to donor plants and are sterile due to the inability of their chromosomes to pair during meiosis. In order to propagate them through seed and to include them in breeding programs, their fertility has to be restored with spontaneous or induced chromosome doubling. The obtained DHs are homozygous at all loci and can represent a new variety (selfpollinated crops) or parental inbred line for the production of hybrid varieties (crosspollinated crops). In fact, cross pollinated species often express a high degree of 
inbreeding depression. For these species, the induction process per se can serve not only as a fast method for the production of homozygous lines but also as a selection tool for the elimination of genotypes expressing strong inbreeding depression. Selection can be expected for traits caused by recessive deleterious genes that are associated with vegetative growth. Traits associated with flower fertility might not be related and should be eliminated by recurrent selection among $\mathrm{DH}$ lines. The production of pure lines using doubled haploids has several advantages over conventional methods. Using DH production systems, homozygosity is achieved in one generation, eliminating the need for several generations of self- pollination.

The time saving is substantial, particularly in biennial crops and in crops with a long juvenile period. For self-incompatible species, dioecious species and species that suffer from inbreeding depression due to self-pollination, haploidy may be the only way to develop inbred lines. The induction of DH lines in dioecious plants, in which sex is determined by a regulating gene, has an additional advantage. Such a case is well studied in asparagus, in which sex dimorphism is determined by a dominant gene M. Female plants are homozygous for the recessive alleles $(\mathrm{mm})$, while male plants are heterozygous (Mm). Androgenically produced $\mathrm{DH}$ lines are therefore female (mm) or 'supermale' (MM). An advantage of supermales is that, when, Used as the pollinating line, all hybrid progeny are male. Haploids from polyploid species have more than one set of chromosomes and are polyhaploids; for example dihaploids $(2 \mathrm{n}=2 \mathrm{x})$ from tetraploid potato (Solanum tuberosum ssp. tuberosum, $2 \mathrm{n}=4 \mathrm{x}$ ), trihaploids $(2 \mathrm{n}=3 \mathrm{x})$ from heksaploid kiwifruit (Actinidia deliciosa, 2n=6x) etc. Dihaploids and trihaploids are not homozygous like doubled haploids, because they contain more than one set of chromosomes. They cannot be used as truebreeding lines but they enable the breeding of polyploid species at the diploid level and crossings with related cultivated or wild diploid species carrying genes of interest

\section{Double Haploid}

Haploid derived from diploids are called monoploid, while haploids derived from poly-haploid. Diploid produced from chromosome doubling of haploids are called doubled or double haploid (DH). DHs can be produced via in vivo and in vitro systems. Haploid plants that underwent spontaneous or induced chromosome doubling. The haploid embryos rescued, cultured and chromosome doubling (using colchicine) for production of doubled haploid.

In conclusion, tissue culture is a very fast technique. Thousands of plantlets can be produced in a few weeks time from a small amount of plant tissue. The new plants produced by tissue culture are disease free. Tissue culture can grow plants round the year, irrespective of weather or season. Very little space is needed for developing new plants by tissue culture. It helps to speed up the production of new varieties into the market place. In case of the seed potato industry, this technique helps in maintaining and establishing virus free stock. So, we have to understand that this technique is important for transforming plants with new genes.

\section{References}

Alan, A. R., Lim, W., Mutschler, M. A. and Earle, E.D. (2007).Complementary strategies for ploidy manipulations in gynogenic onion (Allium cepa L.). Plant Science, 173 (1): 25-31. 
Biniam, T. and Tadesse, M. (2007). A survey of viral status on potatoes grown in Eritrea and in vitro virus elimination of a local variety 'Tsaeda embaba'. African Journal of Biotechnology, 7 (4): 397-403.

Brown, D. C. W. and Thorpe, T. A. (1995). Crop improvement through tissue culture. World J. Microbiol and Biotechnol. 11: 409-415.

Fabre, J. and Dereuddre, J. (1990). Encapsulation Dehydration - A new approach to cryopreservation of Solanum shoot-tips. Cryo-Letters, 11 (5): 413-426.

Hirai, D. \& Sakai, A. (2002). Simplified cryopreservation of sweet potato (Ipomoea batatas (L.) Lam.) By optimizing conditions for osmoprotection. Plant Cell Reports, 21(10), (February 2002), pp. 961-966, ISSN 0721-7714.

Hussain, A., Qarshi, I. A., Nazir, H. and Ullah, I. (2012). Plant tissue culture: Current status and opportunities. Intech. http://dx.doi.org/10.5772/50568.

Ishikawa, M. P., Tandon, A. C., Yamaguishi and Miyazaki, S. (1996). Cryopreservation of bromegrass cells with slow pre freezing and rapid pre freezing methods. Proceedings of the Annual Meeting of Japanese Plant Physiologists, p. 96.

Kharkongar, H. P., Khanna, V. K., Tyagi, W., Rai, M. and Meetei, N. T. (2013). Wide Hybridization and EmbryoRescue for Crop Improvement in Solanum lycopersicum. Agrotechnology doi:10.4172/21689881.S11-004.

Niwata, E., Ito-Ogawa R., Ishikawa, M., and Oosawa K. (1995).Cryopreservation of apical meristems of garlic and high subsequent plant regeneration. CryoLetters 16:102-107.

Tiwari, J. K., Poonam, Sarkar, D., Pandey, S. K., Gopal, J., Kumar, S. R. (2011). Molecular and morphological characterization of somatic hybrids between Solanum tuberosum L. and S. etuberosum Lin. Plant Cell Tissue Organ Culture, 103: 175-187.

Umamaheswai, A, Lalitha V (2007). In vitro effect of various growth hormones in Capsicum annuum $\mathrm{L}$. on the callus induction and production of Capsacium.

\section{How to cite this article:}

Amba Kumari, Dibyanshu Shekhar, M. S. Kundu, Ram Prawesh Prasad, A. P. Rakesh and Chandan Kumar. 2020. Effect of Tissue Culture in Vegetable Improvement. Int.J.Curr.Microbiol.App.Sci. 9(09): 396-404. doi: https://doi.org/10.20546/ijcmas.2020.909.050 